\title{
Cerebral Lactate and $N$-Acetyl-Aspartate/Choline Ratios in Asphyxiated Full-Term Neonates Demonstrated In Vivo Using Proton Magnetic Resonance Spectroscopy
}

\author{
FLORIS GROENENDAAL. REINIER H. VEENHOVEN, JEROEN VAN IIR GROND. \\ GERARD H. JANSEN, THEO D. WITKAMP. AND LINDA S. DI: VRIES

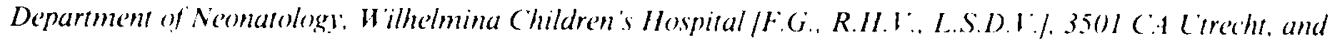 \\ Departmen of Radiodiagnosis /J.I.D.G., T.D. W.J and Department of Patholog! /G.H.J./. Lniversity Hospital. \\ C'trecht. The N'therlands
}

\begin{abstract}
The purpose of this study was to test the hypothesis that a high lactate signal and a low $N$-acetylaspartate/choline ratio in neonates with postasphyxial encephalopathy indicated a high chance of an adverse outcome in vivo when proton magnetic resonance spectroscopy was used. Twenty-one full-term asphyxiated neonates were examined at a mean postnatal age of $7.1 \mathrm{~d}$. Five patients died, and five survivors had handicaps. Eleven of the $\mathbf{1 6}$ survivors (seven without handicaps and four with handicaps) had a second examination at 3 mo of age. After magnetic resonance imaging, spectra were obtained at $\mathbf{1 . 5}$ tesla. A 20 -mm-thick slice was selected through the basal ganglia. After optimizing the B-0 field, we used a double spin-echo pulse sequence $\left(90-180-180^{\circ}\right)$ with a time to repeat of $2000 \mathrm{~ms}$ and a time to echo of $272 \mathrm{~ms}$. Twodimensional spectroscopic imaging was performed by $32 \times$ 32 phase encoding steps in two directions in a $225-\mathrm{mm}$ field of view, resulting in 1-mL volumes, followed by computerized processing. Neuromotor development was examined at $6 \mathrm{wk}, 3 \mathrm{mo}$, and every 3 mo thereafter. Lactate resonances were seen only in the five patients with grade 3 postasphyxial encephalopathy. Lactate was distributed diffusely $(n=4)$, or localized in areas of infarction $(n=$ 1). $N$-acetyl-aspartate/choline ratios were significantly lower in the patients with an adverse outcome than in the survivors without handicaps, both neonatally $(p<0.005$, Wilcoxon's rank sum test) and at 3 mo $(p<0.05)$. In conclusion, the presence of cerebral lactate and a low $N$ acetyl-aspartate/choline ratio demonstrated in vivo using proton magnetic resonance spectroscopy in full-term neonates with postasphyxial encephalopathy indicate a poor outcome. (Pediatr Res 35: 148-151, 1994)
\end{abstract}

\section{Abbreviations}

Cho, choline

'H-MRS, proton magnetic resonance spectroscopy

${ }^{1} \mathrm{H}$-MRSI, proton magnetic resonance spectroscopic imaging

MRI, magnetic resonance imaging

NAA, $N$-acetyl-aspartate

PRESS, point-resolved spectroscopy

TE, time to echo

TR, time to repeat

PAE, postasphyxial encephalopathy

Received April 6, 1993; accepted August 31, 1993.

Correspondence: Dr. F. Groenendaal. Department of Neonatology, Wilhelmina 'hildren's Hospital, P. O. Box 18009, 3501 CA Utrecht. The Netherlands.
MR, magnetic resonance

With 'H-MRS, lactate resonances and a decrease of the NAA/ Cho ratio could be demonstrated in vivo in adults with unilateral hypoxic-ischemic brain lesions and subsequent handicaps days to months after the insult (1-6). 'H-MRSI showed the presence of lactate to be confined to the area of infarction (2). Also, in infants and children with near drowning, cerebral lactate has been demonstrated in vivo in those with permanent handicap (7). In neonates with perinatal asphyxia, only one group described findings of 'H-MRS $(8,9)$. In the neonates with adverse outcome. a lower NAA/Cho ratio was found than in neonates with a normal neuromotor development, but lactate resonances could not be demonstrated in any of their neonates (8).

In accordance with the findings in adults with brain ischemia and in infants with near drowning, we hypothesized that the presence of a high lactate resonance and a low NAA/Cho ratio in the cerebrum of the newborns with PAE indicated a high chance of an unfavorable outcome.

\section{PATIENTS AND METHODS}

In 1992. 21 full-term neonates were examined who had been admitted immediately after birth to our neonatal intensive care unit because of perinatal asphyxia. These full-term infants had postconceptional ages of 39 to $42.3 \mathrm{wk}$ and birth weights of 2430 to $4475 \mathrm{~g}$. All had a well-documented history of perinatal asphyxia, which was indicated by $\mathrm{pH}$ values of umbilical blood samples below 7.10,5-min Apgar scores below 6, and the need for resuscitation by positive pressure ventilation after birth followed by PAE. PAE was graded as grade 1 in 2 neonates, grade 2 in 14 neonates, and grade 3 in 5 neonates, according to the criteria of Sarnat and Sarnat (10). Ethical approval was granted by the Ethical Committee of the Wilhelmina Children's Hospital and of the Utrecht University Hospital.

All patients were transported from the Wilhelmina Children's Hospital to the MR unit of the Utrecht University Hospital in a transport incubator. Additional sedation was not given to any of the neonates. The patients tested at 3 mo of age were sedated with an intramuscular injection of $2 \mathrm{mg} / \mathrm{kg}$ pethidine, $0.5 \mathrm{mg}$ / $\mathrm{kg}$ chlorpromazine, and $0.5 \mathrm{mg} / \mathrm{kg}$ promethazine. Heart rate, respiration, and transcutaneous oxygen saturation were monitored continuously during the procedure and for at least $12 \mathrm{~h}$ thereafter in the sedated patients. Average age at test was $7.1 \mathrm{~d}$ (range, 1 to $20 \mathrm{~d}$ ) for the neonates and $94 \mathrm{~d}$ (range, 81 to $101 \mathrm{~d}$ ) for the 3-mo-old infants. 
Studies were performed on a commercial 1.5 tesla whole-body system (Gyroscan S15, Philips Medical Systems, Best, The Netherlands) with a Helmholtz head coil of $30 \mathrm{~cm}$ diameter. Standard spectroscopy acquisition software was used. First, sagittal T1 (TR $=450 \mathrm{~ms}, \mathrm{TE}=30 \mathrm{~ms})$ and transversal $\mathrm{Tl}(\mathrm{TR}=2500 \mathrm{~ms}$, inversion time using inversion recovery pulse sequence $=800$ $\mathrm{ms}, \mathrm{TE}=30 \mathrm{~ms}$ ) and $\mathrm{T} 2$ ( spin echo, $\mathrm{TR}=3000 \mathrm{~ms}, \mathrm{TE}=50$, $150 \mathrm{~ms}$ ) images were made with a field of view of $225 \times 225$ $\mathrm{mm}$, a slice thickness of $5 \mathrm{~mm}$, and slice factor of 1.2. Thereafter, a PRESS sequence was used for volume selection, with a slice thickness of $20 \mathrm{~mm}$ and a maximum width and length, carefully avoiding contact with the bone of the skull (Fig. 1). Local optimizing the B-0 field was performed by optimizing the proton signal from water to a half-height line width of $0.1 \mathrm{ppm}$.

First, a 'H-MR spectrum of the whole PRESS volume was acquired using a double-water elimination Fourier transform for water suppression, followed by a PRESS double spin-echo sequence $\left(90-180-180^{\circ}\right)(2)$. Relevant parameters were a TR of $2000 \mathrm{~ms}$ and an TE of $272 \mathrm{~ms}: 64$ signals were averaged; 512 time points were taken; and the sampling band width was 1000 $\mathrm{Hz}$. The data were processed by applying Lorenz-Gauss windowing in the time domain (exponential narrowing $4 \mathrm{~Hz}$ and gaussian broadening $6 \mathrm{~Hz}$ ) for noise reduction and spectral resolution enhancement, followed by zero-filling to 2048 data points. Ad-
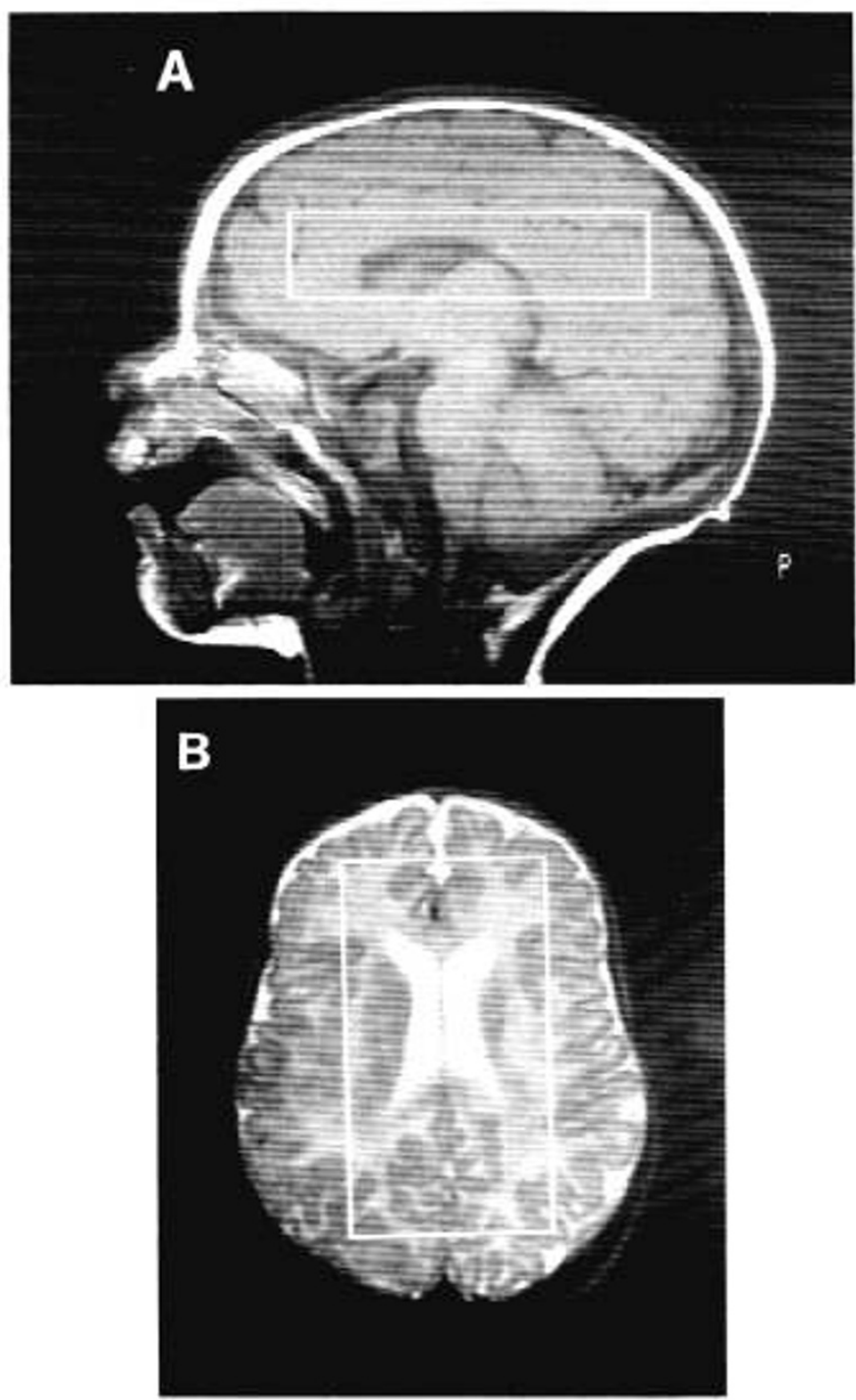

Fig. 1. Position of the PRESS volume in the cerebrum. A slice thickness of $20 \mathrm{~mm}$ is chosen, and contact with the skull is avoided. Sagittal $\mathrm{T} 1(A)$ and transversal $\mathrm{T} 2$ sections $(B)$ through the brain. ditional water suppression was applied by the data-shift-accumulation method (11). The ratio of the peak heights to baseline of NAA and Cho was calculated.

Second, volume-selective two-dimensional spectroscopic imaging was performed with 32 phase encoding steps in two directions, resulting in volumes with a nominal size of $1 \mathrm{~mL}$. Spectroscopic images were created by integration over selected spectral regions with use of special software (12). The spectroscopic data were processed identically as the single volume experiments to obtain metabolic maps. However, no zero-filling was applied in the time domain, but zero-filling to $128 \times 128$ was applied in two-dimensional $\mathrm{K}$ space.

With the use of this pulse sequence, resonances of NAA at $2.02 \mathrm{ppm}$. Cho at $3.25 \mathrm{ppm}$, creatine and phosphocreatine at 3.0 ppm, and-when present-lactate at $1.33 \mathrm{ppm}$ could easily be identified. Lactate resonances were demonstrated by the typical doublet with a $\mathrm{J}$-coupling of $7 \mathrm{~Hz}$ and the resonance occurring at the point of chemical shift for lactate $(1.33 \mathrm{ppm})$, ruling out the possibility that mobile lipids gave rise to these resonances.

\section{RESULTS}

Neurodevelopmental outcome. Five patients died, all because of extensive cerebral damage, which was diagnosed clinically and by cerebral ultrasonography, EEG, and evoked potentials on which supportive treatment was withdrawn. Five others showed abnormalities at neurodevelopment: four had spastic quadriplegia, and one had psychomotor retardation. In addition, mental retardation was found in two infants, and one had severe seizures at 4 mo of age.

Magnetic resonance. MRI showed multiple cerebral infarcts in one patient who died, and abnormal areas in the basal ganglia were noted in another. Hematomas around the cerebellum were seen in two grade 2 patients. Neonatal MR images of the other patients did not demonstrate any abnormalities.

MR images obtained when the infants were 3 mo of age showed dilated ventricles, delayed myelination, and cortical atrophy in the five patients with handicaps.

Magnetic resonance spectroscopl: Lactate resonances with a height of at least $50 \%$ of the NAA resonance could be demonstrated only in the PRESS volume in all five patients with severe PAE, ages 1 to $6 \mathrm{~d}$ (Fig. $2 A$ ). A normal spectrum of a 2-wk-old control neonate illustrates the absence of lactate (Fig. $2 B$ ).

Spectroscopic imaging showed a diffuse signal of lactate extending over the region of the thalami/basal ganglia and the surrounding brain parenchyma in four patients with grade 3 PAE (Fig. 3). Ventricles could not be identified in the spectroscopic image in these patients, probably because of the reduction in ventricular size caused by edema. One patient showed a lactate signal in areas of localized infarction.

The mean NAA/Cho ratios $( \pm \mathrm{SD})$ of the PRESS volume were $0.98 \pm 0.13,0.79 \pm 0.09$, and $0.72 \pm 0.14$ for neonates with normal outcomes, handicaps, and death, respectively (Fig. 4). The differences between neonates with a normal and an adverse outcome (i.e. handicaps or death) were significant $(p<0.005$, Wilcoxon's rank sum test). The NAA/Cho ratios at 3 mo were $1.68 \pm 0.33$ and $1.23 \pm 0.25$ for infants without and with handicaps, respectively. These differences are also significant $(p<0.05)$

\section{DISCUSSION}

Lactate resonances with a height of at least $50 \%$ of the NAA resonance could be demonstrated in all 5 patients with grade 3 PAE but in none of the 16 patients with less severe degrees of PAE. Small peaks at or around $1.33 \mathrm{ppm}$ could be seen in some infants, but because these resonances could not be differentiated from background noise, they could not be regarded as indicative of high lactate concentrations. All patients had normal blood gas values and normal blood lactate values and were normoglycemic at the time of ${ }^{1} \mathrm{H}$-MRSI, so it is unlikely that lactate was trans- 
A

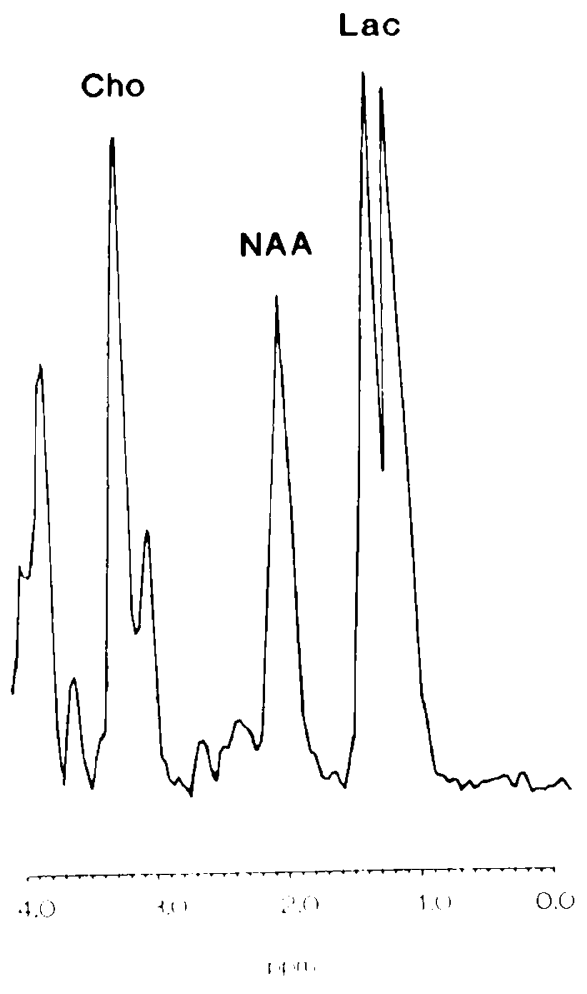

B

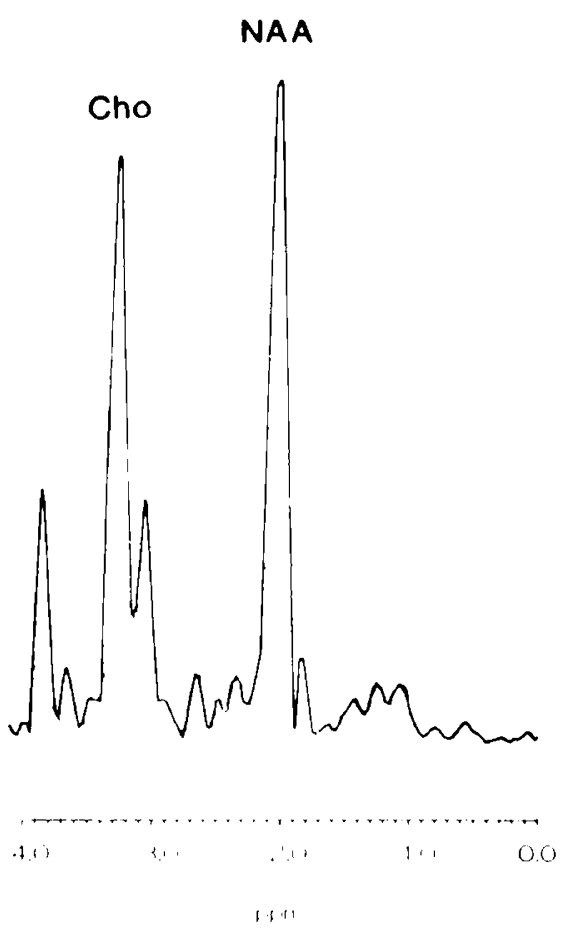

Fig. 2. 'H-MR spectrum of the PRESS volume of a neonate with grade 3 PAE (A) and the spectrum of a neonate with a normal outcome (B). Spectra are presented of the PRESS volume of a neonate with grade 3 PAE (A) and a 2-wk-old neonate with grade 1 PAE and a normal outcome $(B)$. The 'H-MR spectra of the PRESS volume demonstrate resonances of Cho at $3.25 \mathrm{ppm}$. total creatine at $3.0 \mathrm{ppm}$. NAA at 2.02 ppm, and lactate (Lac) at $1.33 \mathrm{ppm}$ (only in .1).

ferred from the blood into the brain. Lactate levels in cerebrospinal fluid were not measured at the time of 'H-MRSI. The lactate resonance could be caused either by lactate produced in the parenchyma by cerebral hypoperfusion; ischemia in the border zones of infarcted areas, the so-called ischemic penumbra: or phagocytic glial cell activity with anaerobic glycolysis (2).

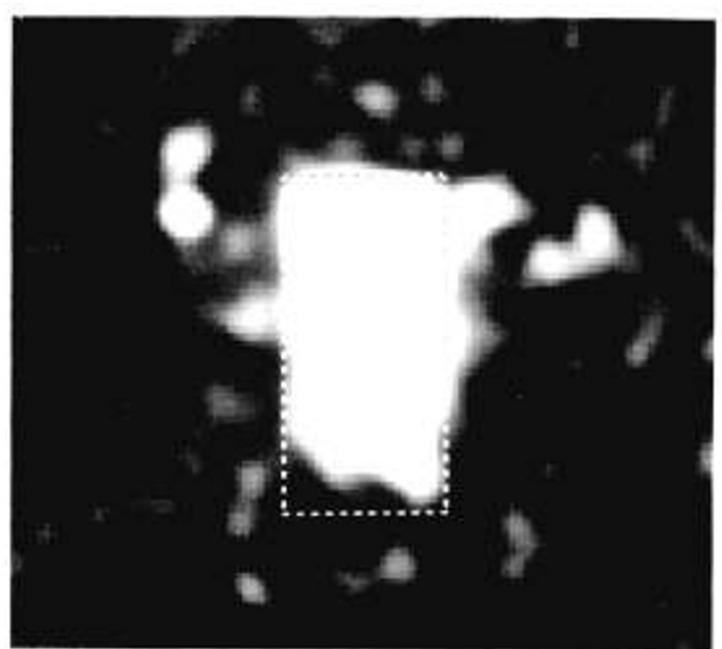

Fig. 3. 'H-MRSI demonstrates lactate to be distributed evenly over the PRESS volume of a neonate with grade 3 PAE. Borders of the PRESS volume are indicated and are similar to those in Figure $1 B$. Ventricles cannot be identified, most likely because of ventricular compression by cerebral edema. White spots outside the PRESS volume are caused by artifacts.

\section{H-MRS}

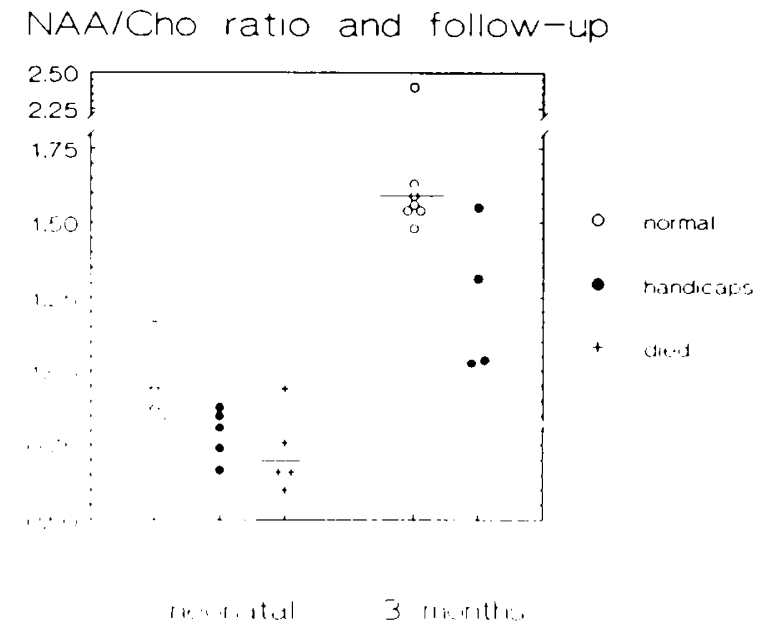

Fig. 4. NAA/Cho ratios are plotted according to postnatal age (neonatal, $3 \mathrm{mo}$ ) and outcome. Differences between neonates with a norma! and adverse outcome (handicaps or death) are significant both in the neonatal period ( $p<0.005$. Wilcoxon's rank sum test) as well as at 3 mo $(p<0.05)$.

Although some gliosis was present in histologic analysis at postmortem examination, it is unlikely that the relatively small number of phagocytotic cells created the high lactate resonances. With our methods, it was not possible to differentiate among the possibilities of lactate trapped in an infarcted. hypoperfused area or continuous lactate production in the ischemic penumbra.

All patients were treated with antiepileptic drugs and showed no clinical convulsions. From June 1992 onward, cerebral electric activity was monitored with the so-called cerebral function monitor, a one-channel compressed EEG device (13). Continuous seizure activity was not demonstrated in any of our patients, so it is unlikely that prolonged seizures caused the high lactate resonance.

Our results are in contrast to the findings of Peden $2 t$ al. (8), who did not demonstrate any lactate, although perhaps one of their patients (case 8 ) could have shown a small lactate resonance. It is possible that their patients were not as severely affected, and the fact that none of their patients died support this theory. 
The lactate resonance was localized in the whole PRESS volume in four newborns, including thalamic areas and basal ganglia. Among other areas, these brain areas are sensitive to anoxia, as is shown in rhesus monkeys and human newborns with severe perinatal asphyxia (14-19).

All five patients with PAE 3 died in the neonatal period. Postmortem examination was performed in four of them and revealed extensive diffuse neuronal necrosis in three patients and localized neuronal necrosis in the patient with the multiple infarcts. The areas of necrosis on histologic analysis corresponded to the areas of high lactate signal on MRI. The presence of lactate in areas of hypoxic-ischemic neuronal cell death is compatible with the presence of lactate in adults with ischemic stroke and in children with near drowning (1-7). The absence of lactate did not predict a normal outcome because five neonates without clear lactate resonances proved to have handicaps. It is possible that lactate had been present before MRS was performed. Also, they had prolonged hypoxia, which is known to affect cortical areas primarily $(17,19)$. With the present ${ }^{1} \mathrm{H}$-MRS technique. however, cortical areas cannot be examined because of susceptibility effects, i.e. interference from skin and bone of the skull.

Because NAA/Cho ratios have previously been reported to be of predictive value $(8,9)$, they were calculated from the ' $\mathrm{H}-\mathrm{MR}$ spectra obtained. Peak values were chosen to avoid the influence of different peak widths in individual measurements. So far, normal NAA/Cho ratios in neonates have not vet been obtained in our institute. Normal values at the end of the first month of life are above $0.80(20)$. The NAA/Cho ratios between neonates with a normal or adverse outcome were significantly different. confirming the findings of Peden, et al. $(8,9)$.

One patient who died and who had a high lactate peak had a NAA/Cho ratio of 0.94 , which is within the normal range. This patient, however, was tested at a very early age after the birth asphyxia. As demonstrated in animals and human adults. NAA/ Cho ratios decline hours to days after significant cerebral hypoxia-ischemia $(5,21)$. It is likely that the NAA/Cho ratio in this patient would have been lower if the patient had been tested at a later age. Unfortunately, because of the severity of the neonate's illness, the examination could not be repeated.

Patients with a normal outcome, as well as patients with handicaps, showed an increase in the NAA/Cho ratios in the first $3 \mathrm{mo}$ of life just as normal infants do (20). The increase of the NAA/Cho ratio most likely reflects neuronal maturation. Nevertheless, the differences in ratios remained significant, possibly indicating permanent loss of neurones.

Testing time was limited because of the severity of illness in the neonates and the duration of sedation in the 3 -mo-old infants, which lasted approximately $1.5 \mathrm{~h}$. Thus, we were unable to prolong our ' $\mathrm{H}$-MRSI, which is necessary for precise concentration measurements of NAA. Cho, creatine and phosphocreatine. and lactate. Hüppi et al. (22) have reported NAA. Cho, and creatine and phosphocreatine concentrations in neonatal brain. but because they used short time-echo sequences. which produce different resonance heights, their findings cannot be used for calculation of metabolite concentrations in our patients.

Although neonatal MR images were useful for identifying tentorial hemorrhages, they were of limited value in cerebral ischemia in the immediate postasphyxial period, possibly because of the high water content of the neonatal brain. Parenchymal abnormalities could be found in only 2 of the 10 patients with an adverse outcome. Others using similar MR scanners and scanning sequences have the same experience (23), although one preliminary study with high-field $(2.35 \mathrm{~T})$ spectroscopy claims usefulness of MRI in prognosis after full-term perinatal asphyxia (24).

This report confirms the findings of others that demonstrate that a decrease of the NAA/Cho ratio indicates a risk of an adverse neurodevelopmental outcome. To the best of our knowledge, this report is the first to demonstrate in vivo the presence and distribution of cerebral lactate in full-term neonates with PAE, indicating a hypoxic-ischemic cerebral insult.

\section{RFFFRFNCFS}

1. Bruhn H, Frahm J. Gyngell MI. Merboldt KD. Hanicke W. Satuter R 1989 Cerebral metabolism in man after acute stroke: ne'w observations using localized proton NMR spectroscopy. Magn Reson Med 4:126-1.31

2. Duijn JH. Matson GB. Maudsley AA. Hugg JW. Weiner MW 1942 Human brain infarction: proton MR spectroscopy. Radiology 183:711-718

3. Felber SR. Aichner FT, Sauter R. Gerstenbrand F 1992 Combined magnetic resonance imaging and proton magnetic resonance spectroscops of patients with acute stroke. Stroke 23:1106-1110

4. Ford CC. Grifey RH. Matwivoff NA. Rosenberg GA 1992 Multivoxel 'HMRS of stroke. Neurology 42:1408-1412

5. Gideon P. Henriksen O. Sperling B. Christiansen P. Olsen IS. Jorgensen HS. Arlien-Soborg P 1992 Early time course of $\mathrm{N}$-acetylaspartate. creatine and phosphocreatine. and compounds containing choline in the brain after acute stroke. Stroke 23:1566-1572

6. Graham GD. Blamire AM. Howseman AM. Rothman DI.. Fayad PB. Brass LM. Petroff OAC. Shulman RG. Prichard JW 1492 Proton magnetic resonance spectroscopy of cerebral lactate and other metabolites in stroke patients. Stroke 23:333-340

7. Ross B. Kreis R, Ernst T 1992 (linical tools for the 90): magnetic resonance spectroscopy and metabolite imaging. Iur J Radiol 14:128-140)

8. Peden CJ. Cowan FM. Bryant DJ, Sargentoni J. Cox IJ. Menon IDK. Ciadian DG. Bell JD. Dubowitz. LM 1990 Proton MR spectroscopy of the brain in infants. J Comput Assist Tomogr 14:886-894

9. Peden CJ. Rutherford MA Sargentoni J. Cox IJ. Bryant DJ. Dubowity LM 1993 Proton spectroscopy of the neonatal brain following hypoxic-ischemic injury. Dev Med (hild Neurol 35:502-510

10. Sarnat HB. Sarnat MS 1976 Neonatal encephalopathy following fetal distress. Arch Veurol 33:696-705

11. Roth K. Kimber BJ, Feeney J 1980) Data shift accumulation and alternate delay accumulation techniques for overcoming dynamic range problems. $J$ Magn Reson 41:3()2-3()4

12. Luyten PR. Marien AJH, Van (ierwen PHJ. Den Hollander JA 1990) Localized ${ }^{2} \mathrm{H}$. NMR spectroscopic imaging of the human brain at $15 \mathrm{~T}$. Book of abstracts. Society of Magnetic Resonance in Medicine. Berkeley, ( alifornia. p 1060 (abstr)

13. Bjerre I. Hellstrom-Westas L. Rosin I, Stenningsen N 1983 Monitoring of cerebral function after severe asphyxia in infancy. Arch Dis (Child 58:49) 1002

14. Barkovich AJ $1992 \mathrm{MR}$ and (TT evaluation of profound neonatal and infantile asphyxia. AJNR 13:959-972

15. Dambska M. Dydyk L. Szreter T. Woniewicz J. Myers RI: 1976 Tomography of lesions in newborn and infant brains following cardiac arrest and resuscitation. Biol Neonate 29:194-207

16. Leech RW. Alvord FC 1977 Anoxic-ischemic encephalopathy in the human neonatal period. Arch Neurol 34:109-113

17. Myers RE 1971 Brain damage induced by umbilical cord compression at different gestational ages in monkevs. In: Goldsmith EI. Moor-Jankowski J (eds) Medical Primatology. S Karger. Basel pp 394-425

18. Schneider I1. Ballowitz L. Schachinger H. Hanefeld F, Drozius JU 1975 Anoxi encephalopathy with predominant involvement of hasal ganglia. brain stem and spinal cord in the perinatal period. Acta Neuropathol 32:287-298

19. Volpe JJ 1987 Neurology of the newborn. 2nd Ed. W. B. Saunders. Philadelphia. pp 159_280

20. Van der Knaap MS, Van der Grond J, van Rijen PC. laber JAJ, Valk J. Willemse J 1990 Age-dependent changes in localized proton and phosphorous MR spectroscopy of the brain. Radiology 176:509-515

21. Van Rijen PC, Verheul HB. Van Fchteld CJA. Balazs R, Lewis P. Vasim MM. Tulleken ( $\mathrm{AF} 1991$ Effects of dextromethorphan on rat brain during ischemia and reperfusion assessed by magnetic resonance spectroscops. Stroke $22 \cdot 343-350$

22. Huppi PS, Posse S. I azeyras F. Boesch C. Fusch C. Burri R. Bossi I. Amato M. Herschkowitz N 1992 'H-Spectroscopy in preterm and term newhorns: regional developmental changes in human brain. Pediatr Res 31:205A(abstr)

23. Byrne P. Welch R. Johnson MA. Darrah J. Piper M 1990 Serial magnetic resonance imaging in neonatal hypoxic-ischemic encephalopathy. J Pediatr 117:694-700

24. Steinlin M, Dirr R. Martin E. Boesch ('. Largo RH. Fanconi S. Boltshauser E $1991 \mathrm{MRI}$ following severe perinatal asphyxia: preliminary experience. Pediatr Neurol 7:164-170 